\title{
ZÉ POVOS E PIERROTS: \\ ESTRATÉGIAS VISUAIS NAS REVISTAS POPULARES ILUSTRADAS NO BRASIL NO INÍCIO DO SÉCULO XX
}

POR

Felipe Botelho Correa

King's College London

O ponto de partida deste artigo é a transformação ocorrida em periódicos do tipo revista de variedades na virada do século XIX para o XX, não somente no contexto dos EUA e da Europa ocidental, mas também em grande parte da América Latina. Esse período marca a ascensão das revistas populares ilustradas, que conseguiram alcançar um público mais amplo do que as revistas ilustradas que surgiram na segunda metade do século XIX. Esse foi o período da consolidação das revistas populares como empresas lucrativas que focavam em um público-leitor de grandes proporções, que por sua vez era também um público de consumidores dos produtos que eram anunciados em páginas de denotavam um avanço técnico na impressão das imagens.

Esse avanço ocorreu em grande parte pelo desenvolvimento da técnica de fotogravura chamada half-tone, que foi implementada em larga escala nas imprensas de periódicos nos EUA em 1897 (Taft 446). A técnica dava aos editores a possibilidade de imprimir de forma econômica revistas de alta qualidade gráfica com fotografias, ilustrações, caricaturas, além de textos. É nesse período que as revistas se tornam acessíveis a um novo público-leitor, abrindo espaço para publicações de variedades de alcance nacional e internacional (Mott 25). A mudança no público-leitor das revistas ilustradas levou os editores a buscar conteúdos mais atualizados e adequados, criando modernas formas de identificação com a nova audiência.

No Brasil, essa modernização foi evidente na primeira década do século XX, quando várias revistas ilustradas foram criadas e impressas semanalmente com tiragens que foram crescendo rapidamente. As publicações brasileiras seguiam o sucesso não só das publicações europeias como Le Rire e Simplississimus, e angloamericanas como Puck, mas também o êxito da argentina Caras y Caretas, que fora fundada em Buenos Aires em 1898, e que na primeira década do século XX já chegava a ter tiragens de 100 mil exemplares semanais. ${ }^{1}$

\footnotetext{
1 A tiragem de cada número da exitosa revista argentina era registrada em suas capas semanalmente. Em 1910, por exemplo, todas as tiragens passaram de 100 mil exemplares semanais, com picos que chegaram a 109.700 cópias.
} 
Essas novas publicações se tornavam cada vez menos veículos de apoio a determinados grupos políticos ou partidos que bancavam os custos de edição. As modernas revistas de massa surgiam naquele momento com ambos os pés no mercado consumidor, e tentando atrair o maior número de possível de leitores. De certa maneira, a mudança fez com que a imprensa doutrinária perdesse espaço para um jornalismo que passava então a depender de anunciantes e de um público-leitor que queria ser entretido e informado ao mesmo tempo. Esses pioneiros periódicos eram capazes de circular amplamente no território nacional e chegar a uma audiência que até então não tinha fácil acesso a esse tipo de informação.

Representativos exemplos desse novo tipo de publicação são os semanários FonFon, criado em 1907, e Careta, criado no ano seguinte. Editadas no Rio de Janeiro, essas eram duas das revistas que sugiram num período que predominava aquilo que o historiador Nicolau Sevcenko chamou de movimento de "regeneração" na capital do país, que ele resume em quatro pontos principais: 1) condenação dos hábitos e costumes ligados pela memória à sociedade tradicional; 2) negação de todo e qualquer elemento de cultura popular que pudesse macular a imagem civilizada da sociedade dominante; 3) uma política rigorosa de expulsão dos grupos populares da área central da cidade, que será praticamente isolada para o desfrute exclusivo das camadas aburguesadas; e 4) um cosmopolitismo agressivo, profundamente identificado com a vida parisiense (Sevcenko 30).

De acordo com Sevcenko, esse movimento de regeneração foi simbolizado pela construção da Avenida Central, atual Rio Branco - que cortou o centro da cidade com um bulevar que ia do cais do porto ao Passeio Público -, a lei da vacinação obrigatória e a Exposição Nacional de 1908 (Sevcenko 30). O argumento é de que esses atos do governo pretendiam modificar não só o espaço público da capital, mas também o modo de vida e a mentalidade da sociedade carioca. As evidências que corroboram esse movimento de regeneração não são poucas e já foram estudadas detalhadamente em trabalhos como o de Jeffrey Needell. ${ }^{2}$

Contudo, esse movimento aparece de maneira distinta quando o analisamos pela perspectiva das revistas populares ilustradas que começavam a crescer na mesma época, como é o caso de Fon-Fon e Careta. Enquanto alguns jornais diários estampavam em algumas de suas colunas a famosa frase "o Rio civiliza-se", outras publicações optavam por pintar um quadro diferente das transformações, focando em grande parte nas consequências das reformas para a classe trabalhadora, que formava boa parte do novo público-leitor.

Se a chamada cultura de elite analisada por Needell nos leva para uma belle époque tropical, o mesmo não se pode dizer de boa parte daquilo que surgia nas

Ver Needell, A Tropical Belle Époque.

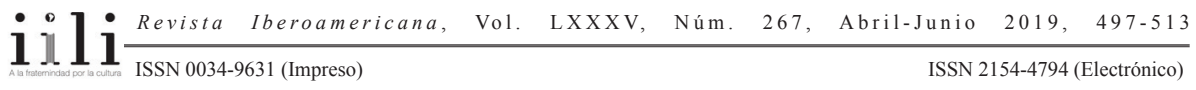


páginas das revistas populares ilustradas. Estas eram eloquentes repositórios de imagens que contrastavam com o espírito de regeneração. Não há dúvida que essas publicações participavam de um processo de modernização que dava novas possibilidades ao desenvolvimento das artes gráficas e da literatura no Brasil. No entanto, essa modernização tinha um caráter distinto que, em oposição à cultura de elite analisa por Needell, enfocava mais a cultura popular.

Ao longo dos quase sessenta anos de edições semanais, que só foram extintas no final da década de 1950, Careta e Fon-Fon foram editadas não somente para aqueles que tinham alto poder aquisitivo, mas também para outros grupos da sociedade brasileira. Essa circulação em massa gerou desafios editoriais como, por exemplo, a necessidade de criar personagens que personificassem a nação, como já havia ocorrido em outros países: Tio Sam (EUA), John Bull (Reino Unido), Marianne (France) e Zé Povinho (Portugal). A questão foi amplamente debatida logo no primeiro ano de circulação de Fon-Fon, quando os editores publicaram artigos de diferentes ilustradores, cada um sugerindo novas formas de personificar a caricatura da nação brasileira moderna.

Ao longo da segunda metade do século XIX, a imagem mais comum utilizada para personificar a nação brasileira era a figura do indígena, que às vezes aparecia combinada com a figura do português ou do europeu. Segundo Lilia Moritz Schwarcz, essa representação que atravessou o romantismo no Brasil, vinha de uma ideia de que o indígena era uma espécie de representante digno e legítimo da nação (Schwarcz, As barbas do imperador 148). Eles representavam a ficção de fundação da nacionalidade, elaborada, por exemplo, na obra literária Iracema (1865) de José de Alencar, e que foi largamente utilizada pelo ilustrador Ângelo Agostini em sua Revista Ilustrada. Na figura, por exemplo, a imagem do indígena aparece erguendo a bandeira da liberdade em cima da estátua equestre de D. Pedro I, para celebrar o aniversário da proclamação da Independência do país.

A figura do indígena como personificação da nação começou a mudar com o surgimento das

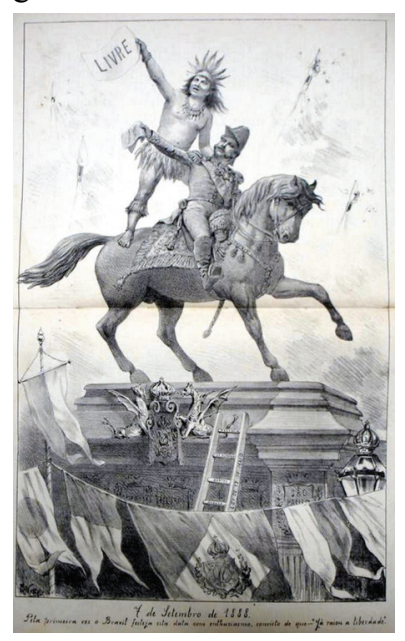

Fig.1 Revista Ilustrada, 8 setembro 1888 revistas populares e comerciais discutidas anteriormente. A abolição da escravidão e o início da República, combinados com a crescente chegada de imigrantes europeus, a modernização regeneradora do Rio de Janeiro e o crescimento de São Paulo abriram caminho para uma população cada vez mais urbana e heterogênea que já não tinha lastro na imagem do indígena.

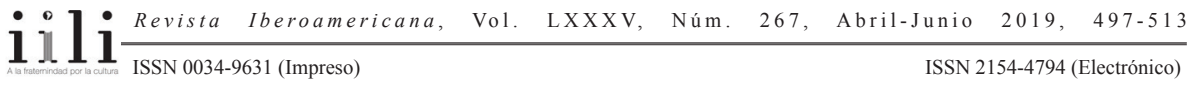


Um dos primeiros a lançar o debate sobre a construção de uma nova identidade cultural foi o caricaturista Calixto Cordeiro, que colaborava com a Fon-Fon:

Há muito tempo discuto com meus amigos e colegas a representação caricatural do Brasil, pois considero que não é mais aceitável a figura com que até agora o temos representado... / É sabido o nosso desenvolvimento progressivo diante das outras nações portanto que de há muito deixamos na taba dos velhos caciques nossos avós, o cocar, a tanga e o tacape que muito nos atrapalhavam na dança guerreira do progresso. [...] / Assim, penso eu, não devemos mais atirar em meio das outras nações vestidas o nosso botocudo envergonhado e nú do passado, tendo na mão o arco ou o tacape. (Fon-Fon, 22 fevereiro 1908)

O próprio tema da revista Fon-Fon já deixava claro que a proposta era de ser um produto da crescente urbanização, simbolizada pelo som de buzina de automóvel que define o seu onomatopaico título. Ao buzinar a modernidade, a revista bota para correr e em seguida atropela aqueles que, vinculados ao passado, caminham pela estrada antiga e estreita, como ilustram as capas das duas primeiras edições da revista logo que foi fundada em abril de 1907.
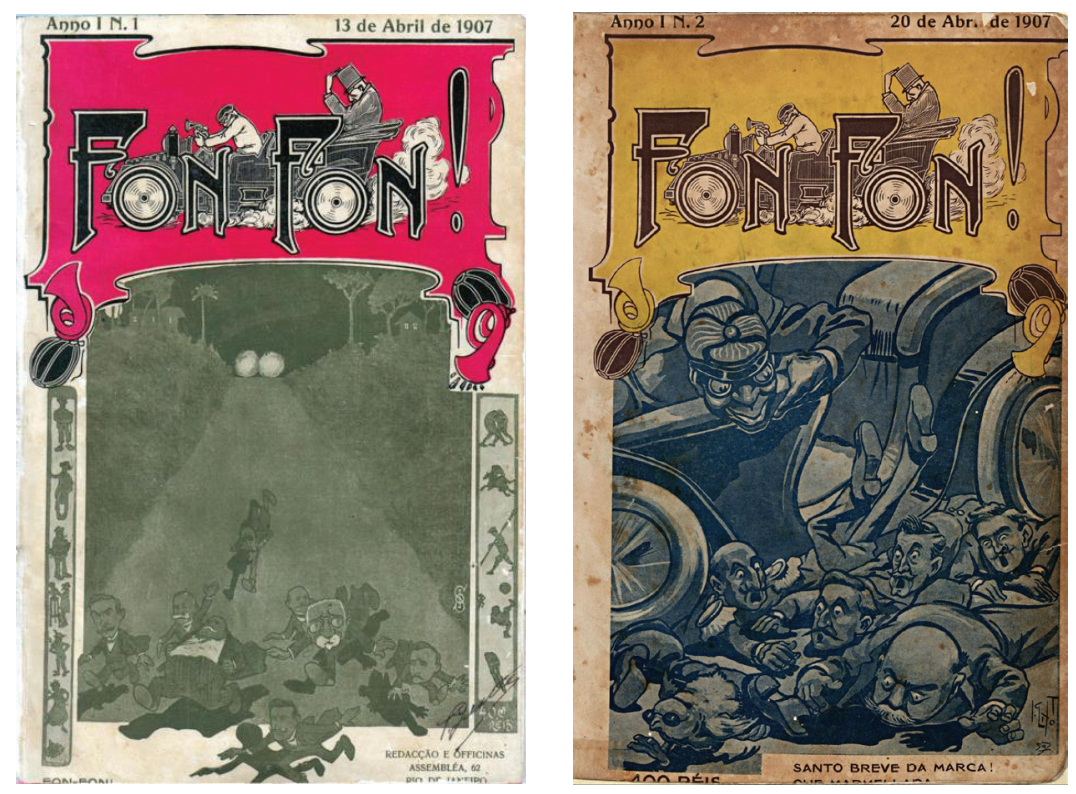

Fig. 2, Fig. 3, Fon-Fon, 13 e 20 abril 1907

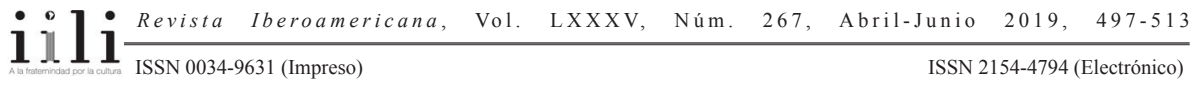


Para os colaboradores da revista, entre eles os ilustradores Deodato Maia, Raul Pederneiras, J. Carlos e escritores como Lima Barreto, a alegoria nacional de um país que se transformava a passos largos deveria evitar o mito indianista e deixar para trás a narrativa do passado pré-colonial, focando na construção de uma identidade cultural que atendesse às demandas de uma população que tinha como base a diáspora europeia e africana que marcou o crescimento da população urbana, e um contexto agora republicano, pós-escravagista e de um emergente capitalismo.

Após alguns meses com vários artigos publicados em Fon-Fon, a sugestão mais acatada entre os colaboradores, e que ganhou força nos anos seguintes, foi a de uma

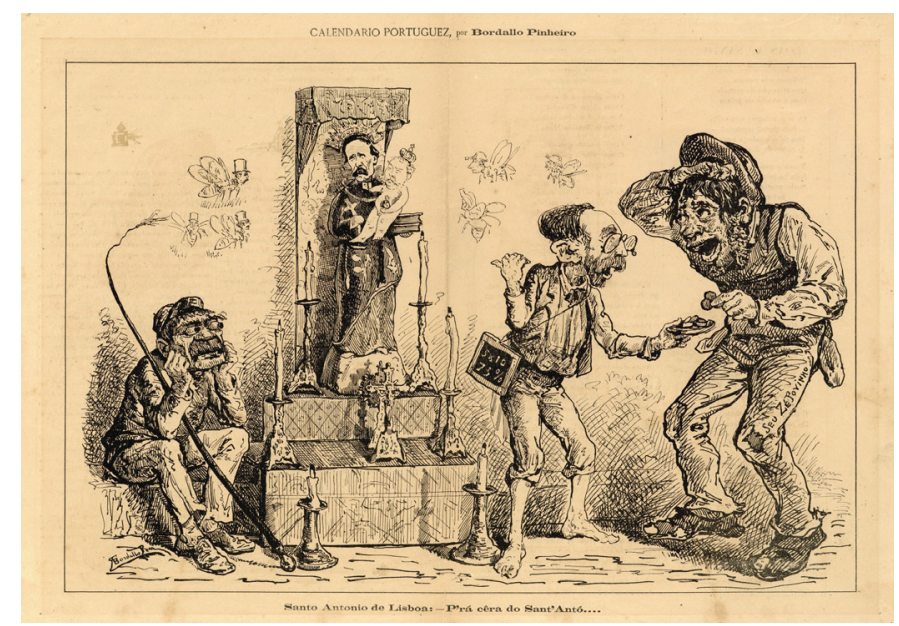

Fig. 4 Zé Povinho, 12 junho 1875 na revista A Lanterna Mágica

adaptação do personagem Zé Povinho, que fora criado pelo português Rafael Bordalo Pinheiro e publicado pela primeira vez em 12 de junho 1875 na revista A Lanterna Mágica.

À direita da imagem, personificando o povo português, o maltrapilho Zé Povinho começa sua vida como vítima do estado que cobra altos impostos. O personagem foi criado como síntese do cidadão português comum, ordinário, e que funcionava como uma espécie de artista cômico e veículo de crítica social e política. Sua indumentária quase sempre era marcada por referências à vida campesina, como símbolo de uma classe trabalhadora rural portuguesa.

Suas idas à cidade eram frequentemente utilizadas para demonstrar como ele se tornava vítima do estado e das autoridades. Longe de simbolizar o império português, que ainda ocupava territórios na África e na Ásia, Zé Povinho era a personificação de homens que levavam uma vida humilde, de desconhecimento dos acontecimentos

\begin{tabular}{l}
111 \\
\hline ISSN 0034-9631 (Impreso)
\end{tabular} 
que o cercavam e que não possuía qualquer autoridade. Zé Povinho era também a imagem de camponeses pobres que, em grande número, acabaram por emigrar para $\mathrm{o}$ Brasil na virada do século XIX para o XX.

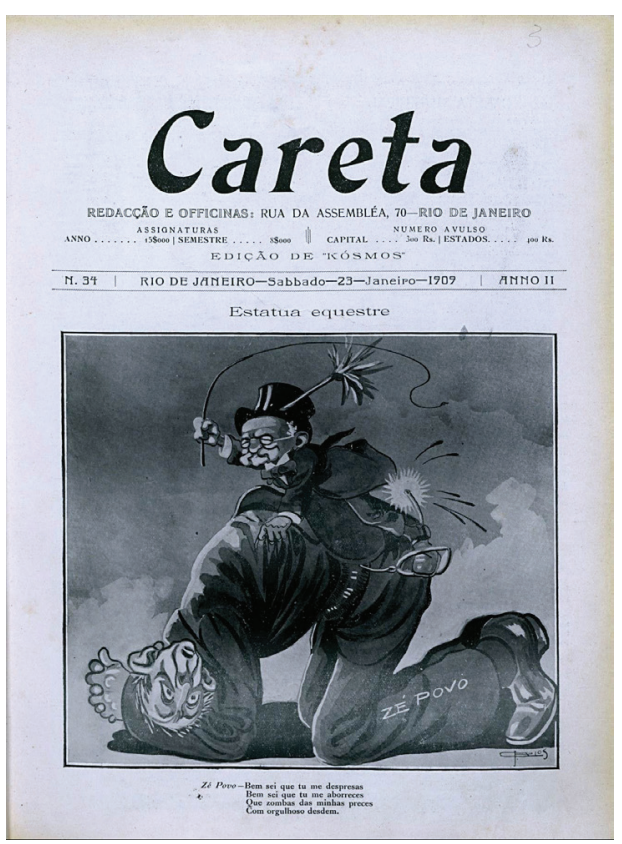

Fig. 5 Careta, 23 janeiro 1909

A variação brasileira desse personagem começou a ser elaborada já na segunda metade da década de 1900 sob o nome de Zé Povo e como constante vítima de instituições como o Congresso Nacional, o Presidente da República e de situações da vida nacional como as cobranças de impostos. Essas instituições e personagens frequentemente aparecem como antagonistas de Zé Povo e abusando do poder muitas vezes de maneira violenta, como sugere a ilustração abaixo de J. Carlos publicada na Careta, em que Zé Povo é montado e chicoteado pelo então Presidente da República Afonso Pena.

Ainda que apareça em situações similares às que Bordalo Pinheiro criava para o Zé Povinho, a versão brasileira do personagem é distinta, principalmente por ser um tipo caracteristicamente urbano num contexto republicano. Zé Povo era, nesse sentido, a personificação de um Brasil que vivia em cidades, miscigenado, que não tinha uma origem bem definida e que se identificava com práticas populares como o carnaval, o samba e a capoeira. Em muitas ocasiões ele aparecia como negro ou mulato, não havendo, contudo, um padrão bem definido nas diversas versões que foram produzidas pelos ilustradores de Careta e Fon-Fon.

Essa mudança de síntese caricata da nação é evidência de um período de transformações nas produções culturais no Brasil, e que anos depois teria mais evidência em grande parte daquilo que foi produzido nas décadas de 1920 e $1930 \mathrm{com}$ o avanço do modernismo e da incorporação da imagem de uma nação miscigenada. O modernismo carioca, no sentido em que sugere Monica Pimenta Velloso (1996), já trabalhava questões como essas nas revistas populares ilustradas, que foram uma importante plataforma para a primeira geração de intelectuais e artistas negros que cresceram num Brasil pós-Lei Áurea e republicano. Para criadores como Calixto Cordeiro, Lima Barreto e Di Cavalcanti, só para citar alguns dos nomes

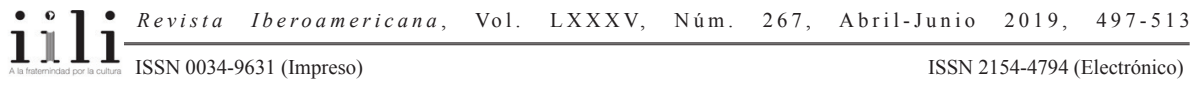


que colaboraram com Fon-Fon, aquele foi um momento de disputa da imagem da "brasilidade" em periódicos que contavam com uma crescente circulação nacional que não tinha precedentes.

Essa incorporação da imagem do negro ao debate sobre a nacionalidade no período após a Abolição foi analisada por Thomas Skidmore em seu pioneiro trabalho de 1974 Black into White e vem, desde então, sendo reavaliada por diferentes ângulos, principalmente em relação ao mito das relações raciais harmoniosas. Outros trabalhos, como O espetáculo das raças, de Lília Moritz Schwarcz, procuraram analisar a ideologia do branqueamento que rejeitava e colocava como tabu a miscigenação tendo como base o chamado racismo científico que tinha como um de seus expoentes o italiano Cesare Lombroso.

Essas e outras pesquisas ajudaram a elucidar as transformações pelas quais passavam a sociedade brasileira naquele início de século XX e o embate de ideias que era travado sobre a questão racial. Contudo, poucos foram os trabalhos que se propuseram a analisar objetos de caráter mais efêmero como as revistas ilustradas e os tipos de discursos que estas comunicavam. No campo de estudos literários, em particular, o enfoque tem sido nos estudos de produção intelectual negra em periódicos que não tinham grande circulação como livros e as chamadas pequenas revistas ou revistas literárias, que passavam longe do impacto que as revistas populares comerciais tinham naquele período.

Ao contrário da ideologia do branqueamento, essas revistas de circulação de massa pintavam a nação com outras cores, frequentemente optando não por embranquecer, mas por enegrecer os conteúdos de suas tiragens semanais, orgulhosamente representando a cultura popular em suas páginas para buscar uma conexão com seu público-leitor. Em meio a um conteúdo de variedades, é possível ver expressões como a capoeira, o samba e o carnaval em quase todas as edições. Em 1909, por exemplo, quando ainda era estigmatizada e definida como crime no Código Penal, os editores de Careta dedicavam páginas inteiras à capoeira. Nas imagens abaixo, o lutador Cyriaco

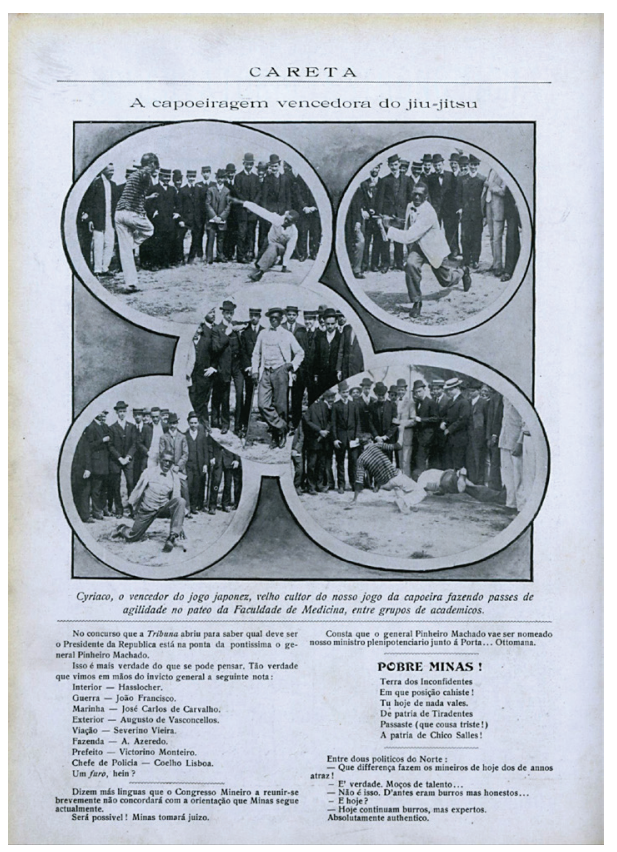

Fig. 6 Careta, 29 maio 1909

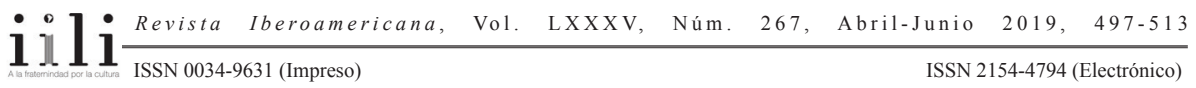


é louvado por sua vitória contra o lutador japonês de jiu-jitsu num combate que teve uma plateia formada por alunos e acadêmicos da Faculdade de Medicina do Rio de Janeiro (Careta, 29 maio 1909).

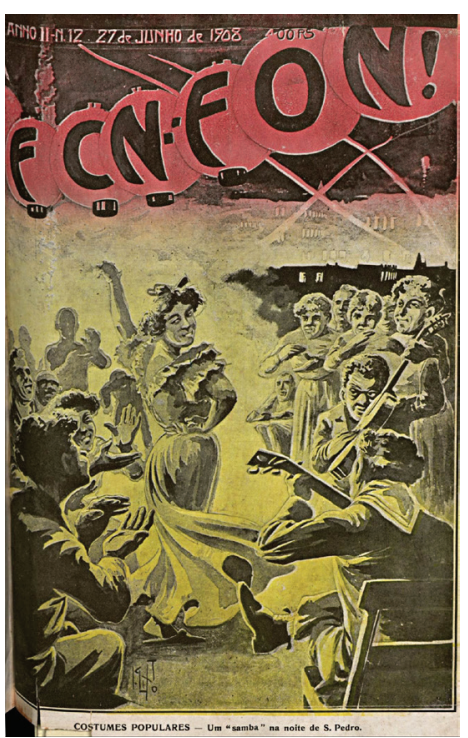

Fig. 7 Fon-Fon 27 junho 1908

Assim como a capoeira, outros elementos da cultura popular rejeitados pelo espírito de regeneração apontado por Sevcenko foram ressaltados em muitas das edições dessas revistas. O carnaval e o violão - que acabaram por se tornar hoje em dia símbolos do Brasil em contextos internacionais - não eram bem vistos naquele começo de século. Como a capoeira, eles eram rejeitados pela regeneração republicana como sendo sinônimos de vadiagem (Sevcenko 32). Esses elementos de cultura popular, muitos dos quais com grande influência da cultura de derivação africana, tinham espaço garantido nessas revistas, como no exemplo da capa da edição abaixo, publicada em 1908, que trata dos "costumes populares" e ilustra uma roda de samba.

Zé Povo, a moderna personificação caricata

do Brasil, se identificava com essas expressões populares mesmo antes de estas terem se tornado símbolos nacionais, algo que somente ocorreu no período em que Getúlio Vargas chegou ao poder na década de 1930, e com maior intensidade a partir de 1937, já no período do Estado Novo.

Nessas revistas de grande circulação do começo do século XX, o samba e o carnaval são momentos de riso que contrastam com o cotidiano hierárquico entre personagens também caricatos como as melindrosas e os almofadinhas, que eram utilizados pelos ilustradores para caracterizar de forma derrogatória os trejeitos das classes

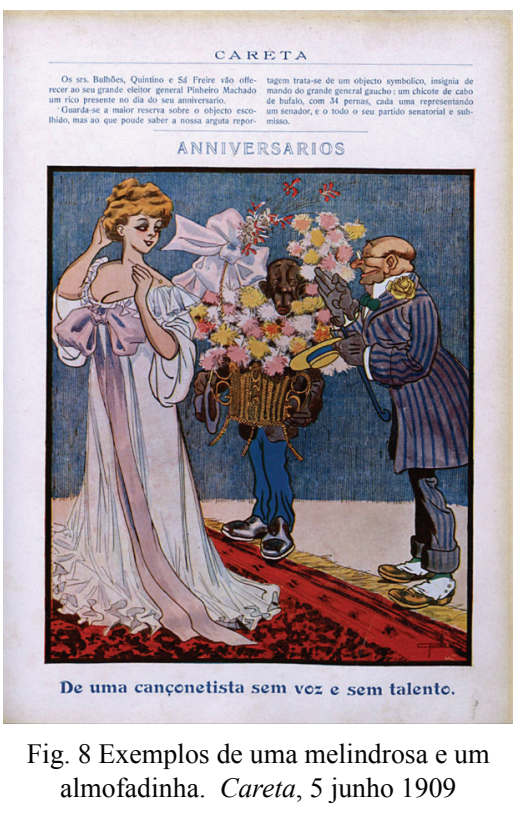

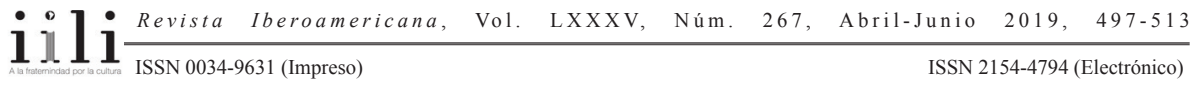


aburguesadas, frequentemente associando-os com absurdos e frivolidades. Representações de Zé Povo por vezes apareciam em grande contraste com esses personagens, ressaltando uma crítica bem-humorada, como pode ser visto na imagem abaixo, em que Zé Povo, amante do samba, aparece no centro do enquadramento, mas quase invisível, escondido pelas flores, no contexto do "Aniversário de uma cançonetista sem voz e sem talento".

Uma estratégia visual mais sutil, sem deixar de ser mordaz, para contrastar as diferentes classes sociais pode ser vista na diagramação de imagens em algumas edições da Careta. Na página abaixo, por exemplo, os casais dançando no baile das colônias inglesa e americana, que aparece na parte superior, contrasta com a "festa

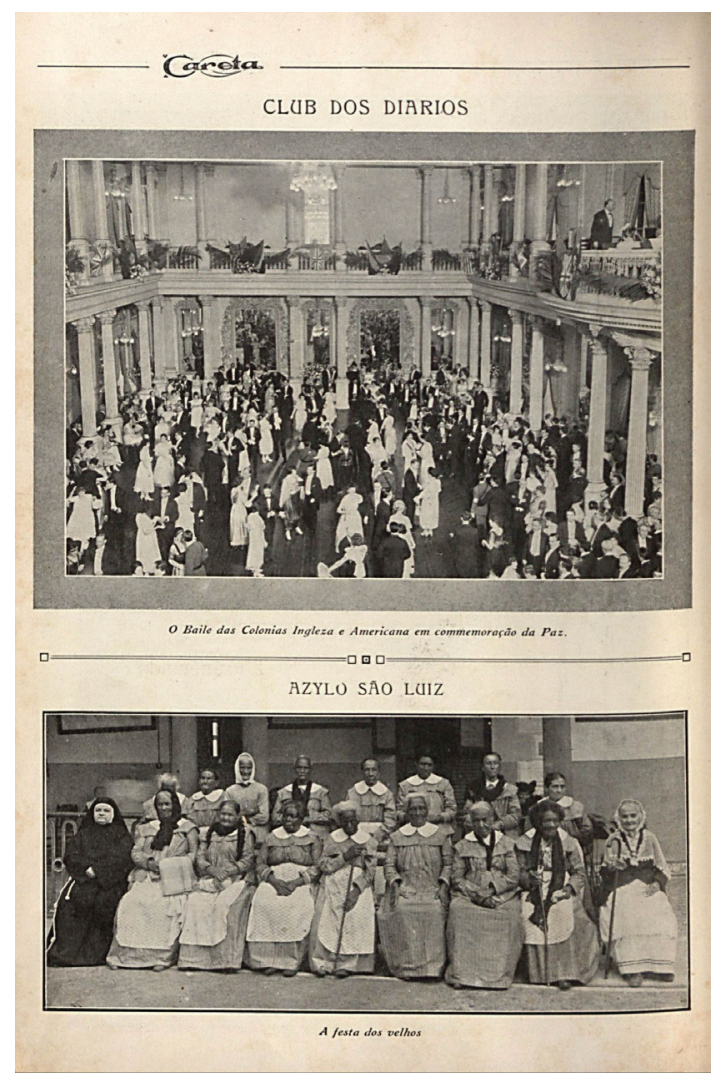

Fig. 9 Parte superior Clube dos diários. O Baile das Colônias Inglesa e Americana em comemoração da Paz.

Parte inferior: Asilo São Luiz. A festa dos velhos. Careta, 6 setembro 1919

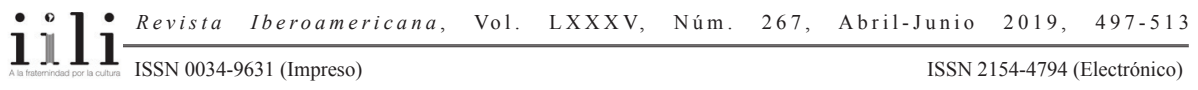


dos velhos" na parte inferior, formada em sua maioria por mulheres negras e de idade avançada que estão em um asilo. Trata-se de um eloquente exemplo de ironia e crítica através da justaposição de imagens que sugere uma proposta de identificação popular que desafia as propostas da regeneração e do branqueamento.

Frequentemente representado como tendo a pele escura, Zé Povo (ou suas versões femininas equivalentes) é a possibilidade tragicômica da representação caricata do Brasil naquele contexto histórico. É essa a perspectiva que muitas vezes aparece nos textos e nas caricaturas semanais: uma mistura de emoções em que as tragédias do cotidiano ou mesmo as tragédias históricas eram apresentadas de maneira bemhumorada, sendo o humor utilizado como ferramenta crítica.

Enquanto políticos, instituições e outros países tendem a aparecer como vilões, os cidadãos anônimos são representados como vítimas, e com a revista quase sempre tomando partido e apoiando Zé Povo. Nas imagens abaixo, por exemplo, Zé Povo aparece em primeiro plano, longe do brilho ensolarado da liberdade, da igualdade e da fraternidade, e preso a um tronco e a um grilhão no aniversário de de vinte e quatro anos da Abolição, com a legenda: "Só ele [Zé Povo] não acha quem o liberte!". $\mathrm{Na}$ imagem à direita, a "politicagem" esmaga com a Constituição a personificação feminina do Estado da Bahia, na mesma posição que Zé Povo aparece em outras ocasiões.
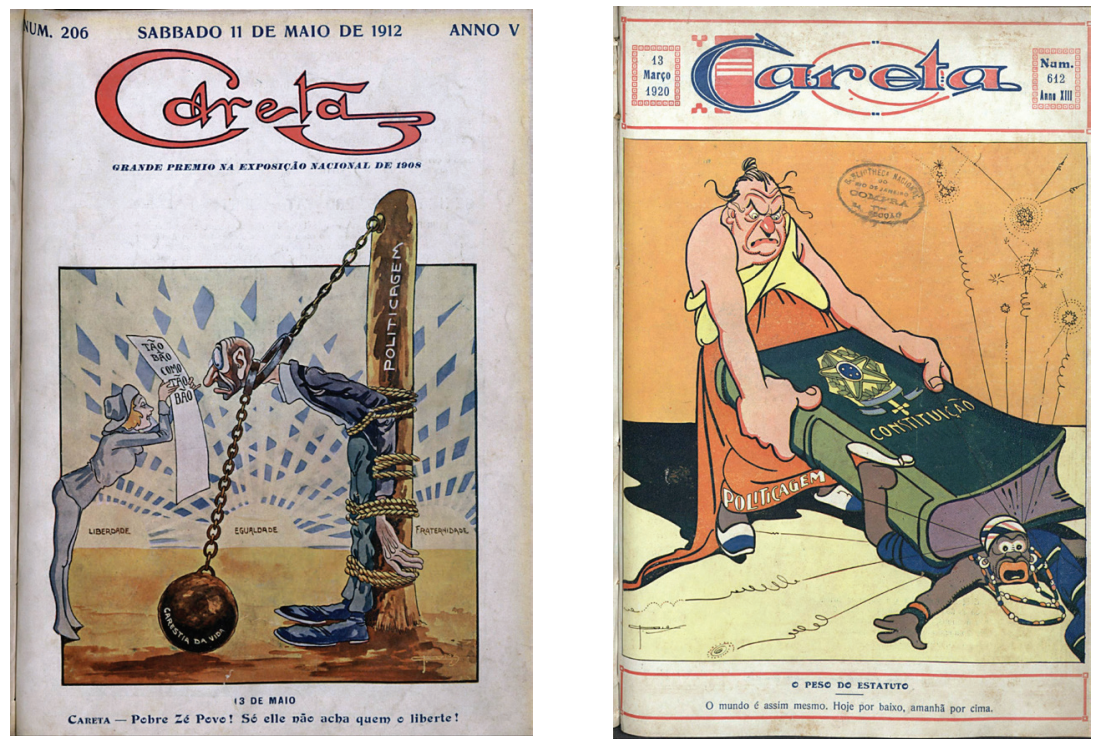

Fig. 10 e Fig. 11

Careta, 11 maio 1912 e 13 março 1920 
Os comentários em relação aos símbolos da regeneração apontados por Sevcenko são eloquentes em relação às estratégias dessas revistas. A Exposição Nacional de 1908, por exemplo, pretendia apresentar o Brasil não mais como um país do futuro, mas como uma nação progressista do presente, como informa o livro oficial do evento, escrito originalmente em inglês:

The significance of the occasion was not lost to the visiting foreigners who witnessed the inauguration of the Brazilian Exposition of 1908. It meant that the old traditions of Europe regarding Latin-American 'lands of tomorrow' would have to be discarded, as no longer applicable; and that at least one of these countries, by the evidence shown in this Exposition, deserves to be classed among the most progressive 'lands of today'. The co-operation of all States in making the Exposition representative of national industry indicates that the spirit of progress is not confined to the most important commercial centres but that it prevails throughout the Republic. (Wright 8)

A visão satírica dos colaboradores da Fon-Fon não era a mesma. Numa das edições que comentaram a Exposição, eles dedicaram a capa à uma crítica bemhumorada da representação da Bahia. Dentro do pavilhão, o Estado foi representado por amostras das madeiras de seus florestas, móveis, pedras preciosas e joias, quadros de pintores baianos, produtos da indústria têxtil, sementes, livros e vistas panorâmicas, praticamente despido de sua histórica relação com a África. Na ilustração abaixo, a personificação da Bahia é uma mulher negra que segura em suas mãos o Pavilhão da
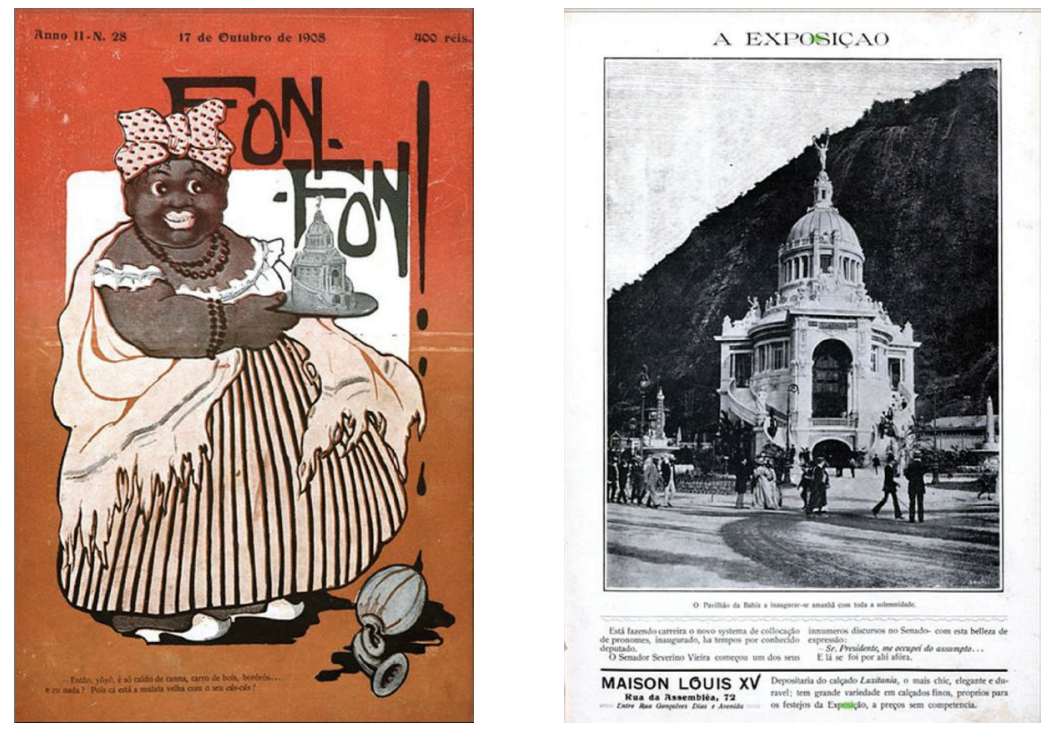

Fig. 12, e Fig. 13

Fon-Fon, 17 outubro 1908

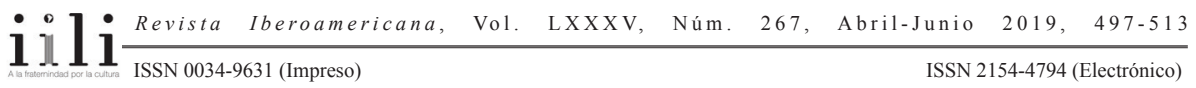



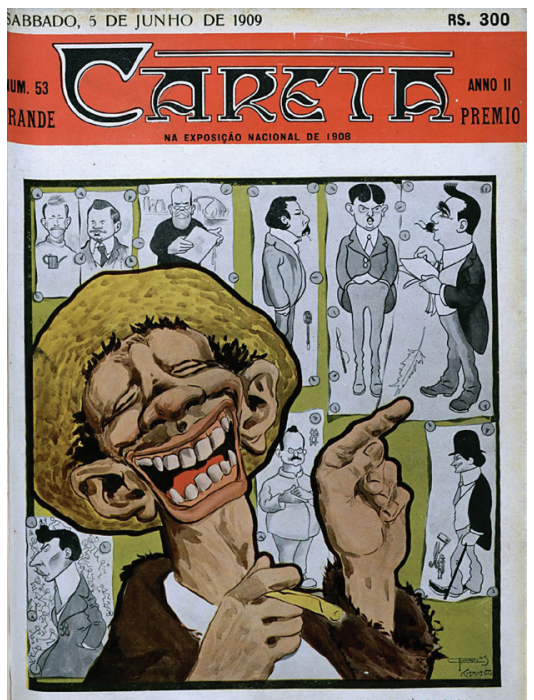

ZÉ POVO, CONSIDERANDO PHILOSOPHICAMENTE GUE SE UM DIA É DA CAÇA,

Fig. 14

"Zé Povo, considerando filosoficamente que se um dia é da caça, o outro é do caçador ri-se das caretas da Careta." Careta, 5 junho 1909
Bahia que foi erguido no bairro da Urca em para a exposição de 1908 e diz: "--Então, ioiô, é só caldo de cana, carro de bois, bororós... e eu nada? Pois cá está mulata velha com o seu cuscuz!" Ao lado, vemos uma fotografia do Pavilhão da Bahia na Exposição Nacional também publicada na revista.

As complexidades e contradições da história brasileira como a escravidão e a corrupção são satiricamente ressaltados nas capas semanais, criando um moderno e inovador repertório para narrar a nação. Nessas situações, a sátira emerge como uma representação tragicômica do cidadão urbano pobre, encarnado em Zé Povo, que é presa fácil de uma caçada contínua e cotidiana que somente em raros momentos é revertida a seu

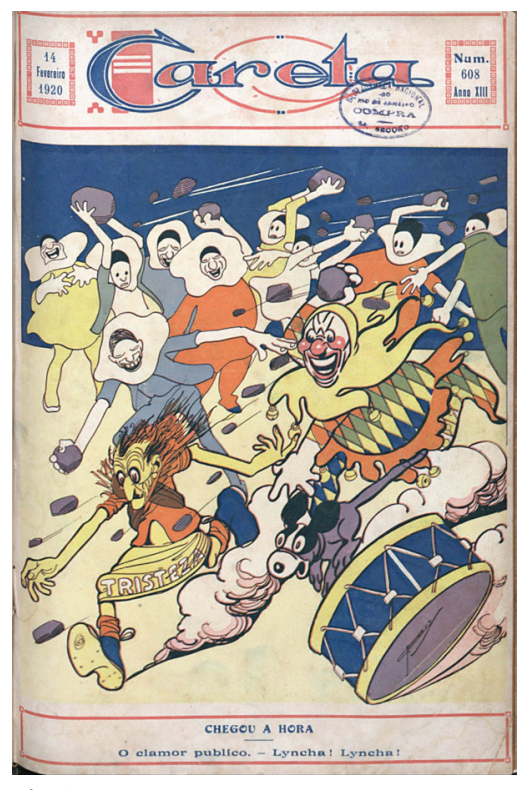

Fig. 15

Careta, 14 fevereiro 1920

favor, quando a caça vira caçador. Esses são os raros momentos em que Zé Povo não é vítima e surge como uma reencenação do bufão da corte com sua licença para falar a verdade de maneira cômica sem o prejuízo de retaliações. Ele ridiculariza os poderosos como um bufão, seguindo uma longa tradição deste arquétipo que confronta e desafia o poder através do humor e da sátira. ${ }^{3}$

A proposta dessas revistas era a de dialogar com o que elas definiram de "público com $P$ maiúsculo", em referência a abrangência da distribuição, cuja maior parte era enviada da capital para outras cidades do país. Em alguns momentos, tanto Careta quanto Fon-

3 Ver Otto, Fools are Everywhere.

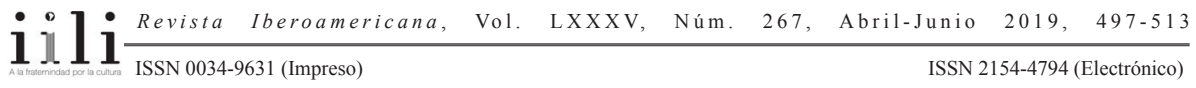


Fon se colocavam como voz do sentimento popular, que é simbolizada pelo carnaval e a tradição burlesca, mas que não se limitava aos três efêmeros dias de festas. Ainda que as referências carnavalescas aumentassem durante o período de festas, com fotografias, ilustrações e textos sobre os tradicionais cordões, bailes, desfiles e o linchamento da tristeza, como na figura abaixo, uma análise panorâmica das edições deixa claro que a subversão humorística do carnaval era replicada semanalmente ao longo do ano.

Além de ser a personificação da figura popular que está nas ruas, Zé Povo é também um personagem que está conectado à tradição satírica, que foi outra estratégia muito utilizada pelos colaboradores dessas revistas para criar uma identificação com a cultura popular e seu público-leitor. Isso fica evidente nas épocas das festas de carnaval, quando Zé Povo dá espaço a personagens-

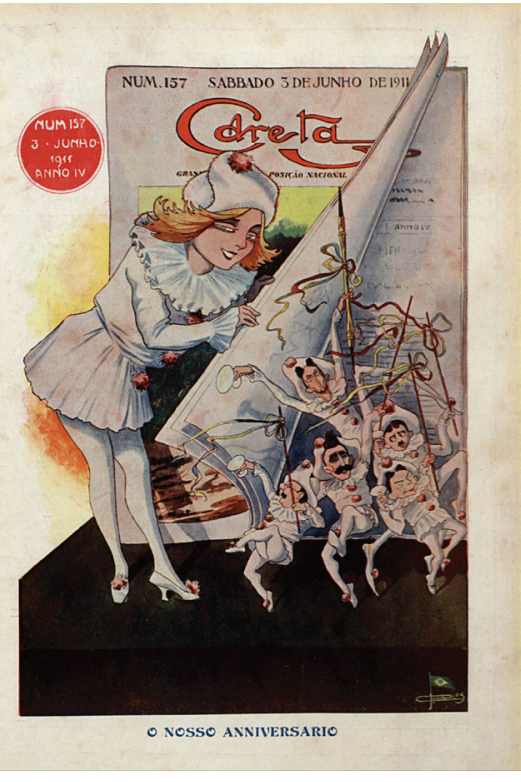

Fig. 16

Careta, 3 junho 1911 tipo como o Pierrot que vem da tradição performática da Commedia dell'Arte.

A ênfase no tema da Commedia dell'Arte nessas revistas não é casual. $\mathrm{O}$ personagem Pierrot já tinha servido a uma variada gama de interpretações até o século XIX que incluía desde o palhaço triste, desentrosado, o artista de rua, a figura pós-romântica que buscava o dramático e a pantomima da vida moderna, até a representação-síntese do moderno proletariado. Nas revistas populares brasileiras, contudo, foi símbolo do carnavalesco e da momentânea subversão das hierarquias sociais.

Ainda que muito presente nessas revistas, as imagens de arlequinada não tinham até então uma história relevante na história da produção visual no Brasil. Os personagens da Commedia dell'Arte não inspiraram os autores românticos, e foi só na época da ascensão das revistas populares ilustradas na virada do século que os temas e personagens começaram a atrair a atenção de escritores e ilustradores, tornando-se um dos temas mais recorrentes e por vezes símbolos dessas revistas, como era o caso da Careta.

A forte presença de Pierrot nessas publicações participava de um contexto mais amplo do chamado culto da Commedia dell'Arte que cresceu primeiro na França se

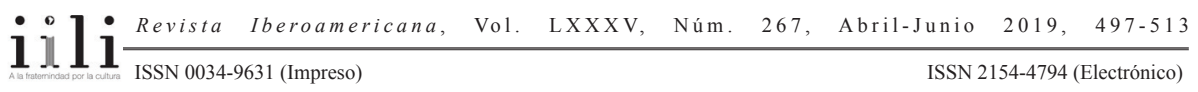




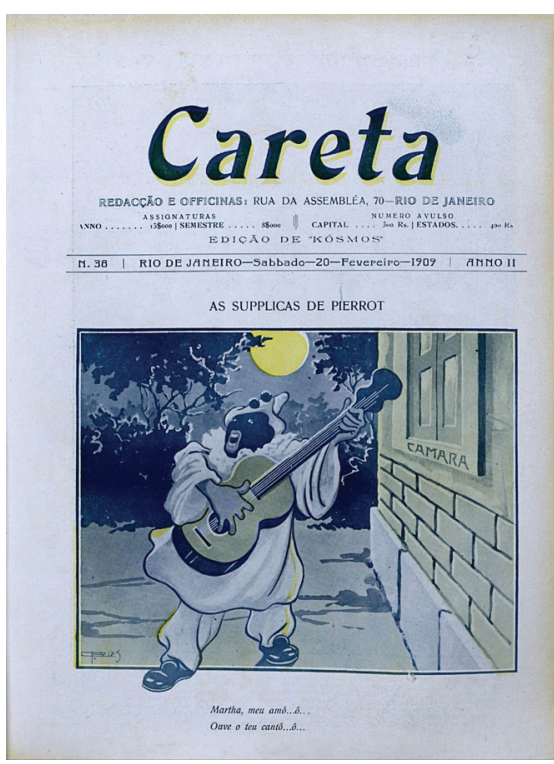

Fig. 17

Careta, 11 janeiro 1913

espalhou por vários países entre as décadas de 1890 e $1930 .{ }^{4}$ No auge desse período, Pierrot se tornou o herói emblemático da sensibilidade do artista da pós-romântico e uma referência comum para os escritores simbolistas e modernistas (Sensibar xvii). ${ }^{5}$

Essa temática serviu de inspiração para inúmeros intelectuais tanto na literatura quanto nas artes visuais tais como Charles Baudelaire, Théophile Gautier, Gustave Flaubert, Stéphane Mallarmé, Paul Verlaine, Adolphe Willette, Jean-Antoine Watteau e Honoré Daumier, que ajudaram a renovar o repertório da Commedia dell'Arte, particularmente do personagem Pierrot, que passou a simbolizar as aspirações não somente do artista e da experiência estética moderna - por sua combinação de riso, tristeza e horror -, mas também um símbolo das classes trabalhadoras (Storey 16).

Os personagens da Commedia dell'Arte, que vem de uma tradição de artistas de rua, tornaram-se naquele momento figuras eloquentes e de apelo popular. Para o escritor, dramaturgo e crítico literário Theophile Gautier, por exemplo, Pierrot era um personagem pálido, magro, vestido com roupas claras, sempre com fome e sempre vencido, e que era símbolo do antigo escravo, do proletário moderno, um pária, um personagem passivo e deserdado que assiste às as orgias e loucuras de uma sociedade da qual é vítima (Gautier 24).

Pierrot, assim como Zé Povo, é um personagem-vítima que aceita a culpa por erros que não cometeu. Ele está quase sempre sozinho ou na periferia do grupo que está no foco da ação, no mesmo tipo de convenção seguida por bufões, que apenas comentam, interpretam e avaliam, mas raramente participam da ação (Storey 27-28).

Naquele período de surgimento das revistas populares ilustradas, Pierrots e Zé Povos eram a tentativa de uma reencenação do espírito bufão de crítica pelo riso, rompendo hierarquias e ridicularizando figuras de autoridade. A geração de intelectuais, escritores e ilustradores que mantinham essas publicações vivas nas

\footnotetext{
Vejase Green \& Swang, The Triumph of Pierrot.

Não me refiro aqui ao movimento modernista brasileiro, mas ao aspecto mais amplo da expressão, que se refere às produções modernas naquele começo de século XX.
}

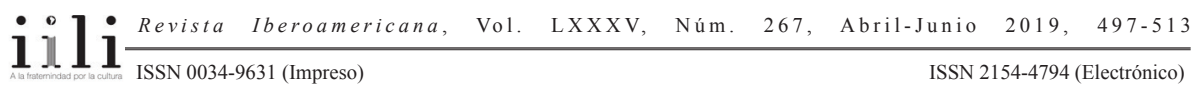


primeiras duas décadas do século XX tinham profunda consciência de que habitavam um mundo marcado pela experiência da modernidade que se acelerou naquele momento no contexto da consolidação da República no Brasil.

O surgimento e a expansão desse novo modelo de publicação periódica que contava com uma circulação e um impacto sem precedentes dava a esses artistas a possibilidade de se fazerem lidos e vistos num momento de intenso debate em relação à reconfiguração das representações da identidade cultural do país. Nesse sentido, os colaboradores dessas revistas foram pioneiros no longo processo de crescente diálogo entre produção intelectual e cultura popular que foi desenvolvido mais tarde pelo grupo da Semana de Arte Moderna realizada em São Paulo.

Publicações como Fon-Fon e Careta, ainda que participassem do período de modernização e regeneração da capital do país, recebendo prêmios e ajudando na expansão das atividades comerciais, afirmavam perspectivas diferentes daquela denominada por Nicolau

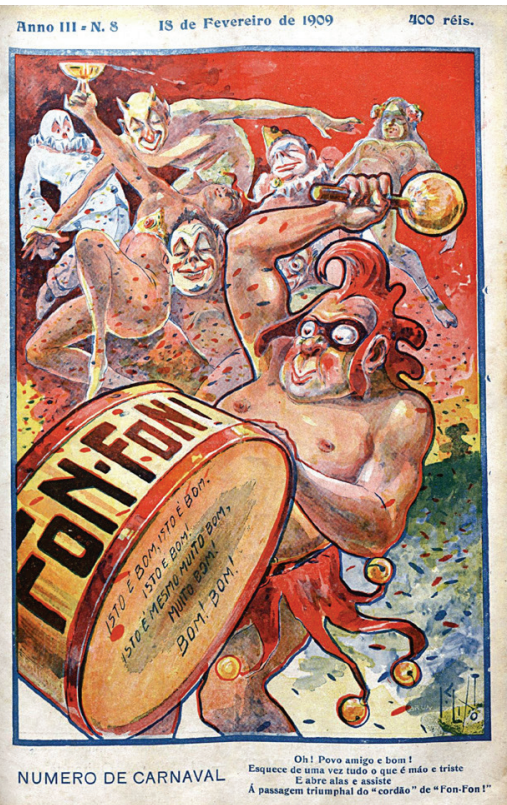

Fig. 18 Sevcenko como espírito de regeneração. Pelos Fon-Fon 15 fevereiro 1909 poucos exemplos analisados neste artigo, é possível ver que há não uma condenação, mas uma afirmação dos hábitos e costumes ligados pela memória à sociedade tradicional. Fica evidente também que há um apoio e uma disseminação de práticas e imagens da ligadas à cultura popular, que passa a ser o centro de um discurso de massa de abrangência nacional identificado com a vida cotidiana de suas cidades, principalmente a capital do país. Ao incorporar a cultura popular e de derivação africana, essas revistas promoviam uma moderna visualidade para a sociedade brasileira, modificando a representação romântica baseada na figura do indígena como símbolo da nação e adotando estratégias satíricas que estavam em constante tensão em embate com uma suposta belle époque tropical. 


\section{BIBLIOGRAFIA}

Alencar, José de. Iracema. São Paulo: Edicões Melhoramentos, 1865.

Careta. Rio de Janeiro, 1908-1960. Disponível em www.memoria.bn.br.

Fon-Fon. Rio de Janeiro, 1907-1958. Disponível em www.memoria.bn.br.

Gautier, Théophile. Histoire de l'art dramatique en France depuis vingt-cinq ans. Volume V. Paris, 1855.

Green, Martin e John Swan. The Triumph of Pierrot: The Commedia dell'Arte and the Modern Imagination. New York: Macmillan, 1986.

Lawner, Lynne. Harlequin on the Moon: Commedia Dell'Arte and the Visual Arts. New York: H.N. Abrams, 1998.

Mott, Frank Luther. A History of American Magazines. Volume IV: 1885-1905. Cambridge: Harvard UP, 1957.

Needell, Jeffrey. A Tropical Belle Époque: Elite Culture and Society in Turn-of-theCentury. Rio de Janeiro. Cambridge: Cambridge UP, 1987.

Nicoll, Allardyce. Masks, Mimes and Miracles: Studies in the Popular Theatre. New York: Cooper Square, 1963.

Otto, Beatrice. Fools Are Everywhere: the Court Jester Around the World. Chicago: U of Chicago P, 2001.

Ritter, Naomi. Art as Spectacle: Images of the Entertainer since Romanticism. Columbia:

Sensibar, Judith. The Origins of Faulkner's Art. Austin: U of Texas P, 1984.

Schwarcz, Lilia Moritz. O espetáculo das raças: cientistas, instituições e questão racial no Brasil, 1870-1930. São Paulo: Companhia das Letras, 1993.

As barbas do imperador: D. Pedro II, um monarca nos trópicos. São Paulo: Companhia das Letras, 1998.

Sevcenko, Nicolau. Literatura como missão: tensões sociais e criação cultural na Primeira República. São Paulo: Companhia das Letras, 1985.

Skidmore, Thomas. Black into White: Race and Nationality in Brazilian Thought. New York: Oxford UP, 1974.

Storey, Robert. Pierrot: A Critical History of a Mask. Princeton: Princeton UP, 1978. Taft, Robert. Photography and the American Scene: A Social History, 1839-1889. New York: Dover Publications, 1964.

Velloso, Mônica Pimenta. Modernismo no Rio de Janeiro: turunas e quixotes. Rio de Janeiro: Editora da Fundação Getúlio Vargas, 1996.

Willeford, W. The Fool and His Sceptre: A Study in Clowns and Jesters and Their Audience. London: Edward Arnold Publisher, 1969.

Wright, M. R. The Brazilian National Exposition of 1908. Philadelphia: George Barrie \& Sons, 1908.

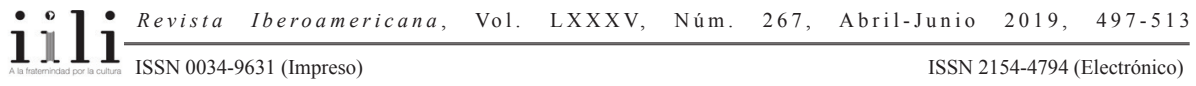


Palavras chave: revistas populares, modernização / tradição, visualidade, Careta, Fon-Fon

Recibido: $\quad$ junho 2016

Aprobado: $\quad$ setembro 2018 
